\title{
NGHIÊN CỨU ỨNG DỤNG ẢNH RADAR TERRASAR-X PHỤC VỤ CÔNG TÁC KIỂM KÊ ĐẢO
}

\author{
ThS. TRÀN TUÂN NGỌC, ThS. NGUYẼN HÀ PHÚ \\ Trung tâm Viễn thám Quốc gia
}

\section{Tóm tắt:}

Việt Nam có đường bờ biển dài hơn 3260 km từ Bắc xuống Nam, dọc theo bờ biển phía Đông - Đông Nam và Tây Nam, vùng biển rộng lớn với khoảng 3000 hòn đảo lớn nhỏ. Các đảo của nước ta phần lớn có diện tích nhỏ nằm dải rác dọc theo bờ biển nên việc kiểm đếm các đảo này là hết sức khó khăn nếu áp dụng các công nghệ truyền thống như đo đạc thực địa hay bay chụp ảnh hàng không. Ảnh radar với đặc tính vật lý riêng biệt nên giá trị bức xạ ngược thu được trên ảnh là rất khác nhau giữa vùng biển và đất liền. Bài báo này giới thiệu phương pháp chiết tách tự động ranh giới giữa mặt biển và đất liền trên ảnh radar để phát hiện và lập bản đồ hình thể đảo trên vùng biển thuộc Vịnh Hạ Long phục vụ công tác kiểm kê đảo. Bài báo cũng phân tích một số nguyên nhân ảnh hưởng đến kết quả chiết tách hình thể đảo tự động trên ảnh radar.

\section{Giới thiệu}

$\mathrm{V}$ iệt Nam với vị trí, đặc điểm của một quốc gia ven biển, có đường bờ biển dài hơn $3.260 \mathrm{~km}$ từ Bắc xuống Nam, dọc theo bờ biển phía Đông - Đông Nam và Tây Nam, vùng biển rộng lớn với khoảng 3000 hòn đảo lớn nhỏ, đặc biệt là có hai quần đảo Hoàng $\mathrm{Sa}$ và Trường Sa nằm án ngữ trên Biển Đông và nằm trong khu vực chiến lược của thế giới. Từ hàng nghìn năm nay, biển - đảo đã gắn liền với sự nghiệp dựng nước và giữ nước của dân tộc Việt Nam. Với đặc điểm địa lý cũng như sự phân bố của các đảo dọc theo bờ biển và xa bờ thì việc kiểm kê đánh giá các đảo về vị trí, hình thể là vấn đề hết sức khó khăn và tốn kém khi áp dụng các phương pháp truyền thống như đo đạc thực địa và bay chụp ảnh hàng không.

Với những ưu điểm như không chịu ảnh hưởng của các điều kiện thời tiết (mây, mưa) cũng như khả năng thu nhận ảnh cả ngày lẫn đêm, ảnh radar có thể được ứng dụng để kiểm kê các đảo trên một khu vực rộng lớn. Trong điều kiện bình thường, mặt nước biển tương đối phẳng lặng đóng vai trò như một vật phản xạ gương hướng phần năng lượng phản xạ ra phía xa khỏi ăng ten thu, trái ngược với hiện tượng tán xạ xảy ra khi tương tác với bề mặt đất. Trên ảnh radar, mặt nước biển xuất hiện với tông màu thẫm so với tông màu sáng hơn của mặt đất. Dựa vào đặc điểm tán xạ sóng radar khác biệt giữa mặt nước và đất liền thì việc chiết tách ranh giới giữa mặt biển và đất có thể làm một cách tự động $[1,2,3]$ thông qua đó hình thể các đảo có thể xác định.

Trong những thập kỷ qua, đã có nhiều nghiên cứu nhằm tự động chiết tách ranh giới giữa mặt biển và đất liền trên ảnh radar hay còn gọi là đường bờ tức thời (instantaneous shoreline). Việc chiết ranh giới mặt biển và đất liền tự động bằng phương pháp xử lý ảnh số liên quan đến vấn đề tìm kiếm đường biên của các đối tượng trong đó hai cách tiếp cận truyền thống là phương pháp tìm kiếm dựa trên đường rìa (edge-based) và phương pháp tìm kiếm dựa trên đối 
tượng ảnh (object-based) [4, 5]. Một số nghiên cứu có thể kể đến như của tác giả Liu và Jerek (2004), Lee và Jurkevic (1990), Mason và Davenport (1996), Baghdagi cùng cộng sự (2004), Halmann và Wessel (2010) cùng một số tác giả khác $[6,7,8,9]$.

\section{Khu vực nghiên cứu}

Khu vực nghiên cứu Hạ Long - Cát Bà có vị trí địa lý trung tâm tại tọa độ 2052’35" vĩ độ Bắc và 10658'01" kinh độ Đông (Hình 1). Vịnh Hạ Long với nhiều hòn đảo lớn nhỏ được công nhận là Di sản thiên nhiên thế giới. Quần đảo Cát Bà có Vườn quốc gia Cát Bà là khu rừng đặc dụng của Việt Nam có sự đa dạng sinh học cao, đã được UNESCO công nhận là khu dự trữ sinh quyển của thế giới. Trong vùng biển này, các hòn đảo lớn nhỏ có cấu tạo chủ yếu là đảo đá. Địa hình khu vực tương đối đa dạng và phức tạp, là một trong những khu vực hình thành lâu đời nhất trên lãnh thổ Việt Nam, bao gồm cả đồi núi, thung lũng, vùng ven biển và hải đảo. Độ cao trung bình khoảng $250 \mathrm{~m}$ trong đó đỉnh cao nhất có độ cao dưới $500 \mathrm{~m}$. Thảm thực vật rừng chủ yếu là kiểu rừng mưa nhiệt đới thường xanh, rừng trên núi đá vôi, rừng ngập nước ngọt trên núi và rừng ngập mặn ven biển và hải đảo.

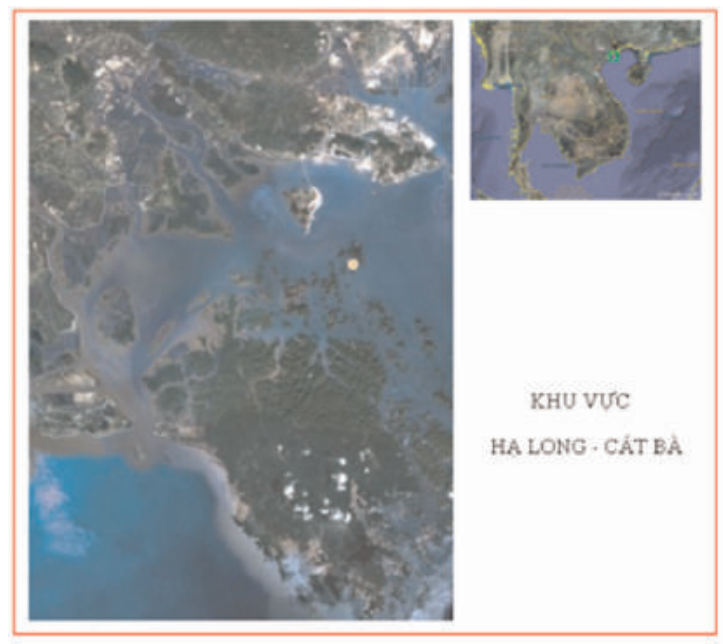

Hình 1: Khu vực nghiên cưu Hạ Long - Cát Bà

\section{Tư liệu và xử lý ảnh vệ tinh radar}

\subsection{Tư liệu}

Tư liệu được sử dụng trong thực nghiệm này là ảnh vệ tinh TerraSAR-X. Vệ tinh quan trắc trái đất TerraSAR-X là sản phẩm của chương trình hợp tác giữa Trung tâm hàng không vũ trụ Đức (German Aerospace Centre - DLR) với công ty EADS ASTRIUM $\mathrm{GmbH}$ (công ty con của Công ty vũ trụ và phòng thủ không gian vũ trụ châu ÂuEuropean Aerospace Defence and Space Company - EADS). Vệ tinh TerraSAR-X hoạt động trên quỹ đạo ở độ cao 514 km. Đây là quỹ đạo cận cực đồng bộ mặt trời với thời gian một chu kỳ lặp là 11 ngày. Vệ tinh TerraSAR-X đầu tiên được phóng vào ngày 15 tháng 06 năm 2007 và bắt đầu cung cấp ảnh quan trắc Trái đất từ tháng 01 năm 2008 với thời gian làm việc trên quỹ đạo dự kiến là 5 năm. Cảnh ảnh TerraSAR-X được lựa chọn là ảnh Stripmap MSD L1B (Multilook Ground Range Detected), thu nhận ngày 02 tháng 05 năm 2012, có phân cực $\mathrm{HH}$, độ phân giải $1.25 \mathrm{~m}$ và góc tới là $46.05^{\circ}$.

Các điểm khống chế ảnh (GCP) và điểm kiểm tra (ICP) trên khu vực thực nghiệm được đo bằng các thiết bị GPS (Global Positioning System) theo phương pháp đo tĩnh cho phép đạt độ chính xác hình học cao. Các điểm khống chế được phân bố đều trên ảnh với tổng số lượng điểm GCP và ICP là 30 điểm. Ngoài ra, bản đồ địa hình tỷ lệ $1: 10.000$ cũng được sử dụng để phục vụ cho việc nắn trực giao ảnh vệ tinh TerraSAR-X.

\subsection{Quy trình xử lý ảnh vệ tinh radar}

Trong phần thực nghiệm này, ảnh radar TerraSAR-X được xử lý trên các hệ thống xử lý ảnh như: phần mềm ERDAS IMAGINE với bộ module phần mềm chuyên dụng để xử lý ảnh SAR là ERDAS IMAGINE's Radar Mapping Suits (RMS), phần mềm ENVI, ArcGIS. Trình tự các bước xử lý có thể được biểu diễn như hình 2. 

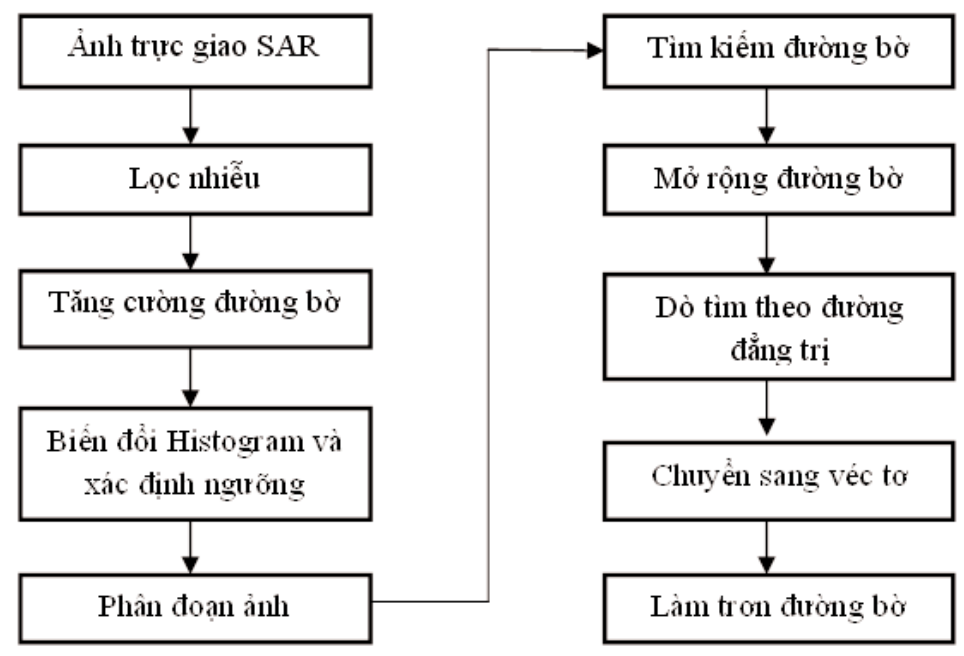

Hình 2: Quy trình tự động chiết tách mặt biển và đất từ ảnh SAR

Trước tiên, ảnh TerraSAR-X được nắn trực giao bằng module phần mềm xử lý ảnh radar RMS trong ERDAS IMAGINE sử dụng các điểm khống chế ngoại nghiệp và mô hình số độ cao. Ảnh sau khi nẳn chỉnh hình học được định vị trong hệ tọa độ VN2000, kinh tuyến trục $108^{\circ}$ theo như quy định thành lập bản đồ địa hình tỷ lệ 1:10.000. Tiếp theo, việc lọc nhiễu được thực hiện bằng cách sử dụng phép lọc Lee được sử dụng tối thiểu 2 lần với cửa sổ kích thước $5 \times 5$ nhằm giảm thiểu ảnh hưởng do những tín hiệu phản hồi có màu sáng trên nền mặt biển mầu thẫm gây ra bởi mặt sóng nhấp nhô.

Để tăng cường khả năng phân biệt giữa biển và đất liền, mặc dù bất kỳ phép lọc tìm kiếm đường rìa nào cũng có thể cho kết quả tốt, tuy nhiên phép lọc Sobel sẽ được sử dụng do các đường rìa tìm được nổi bật và rất phù hợp với cửa sổ kích thước $3 \times 3$. Các đường rìa tìm kiếm được sau đó sẽ được thêm vào $70 \%$ giá trị pixel từ ảnh gốc để tăng cường các đường rìa phân biệt giữa mặt đất và mặt nước (đường bờ) trong khi vẫn không ảnh hưởng đến các đường rìa khác trên mặt đất. Đồng thời, phép lọc Mean với cửa sổ kích thước $5 \times 5$ cũng được thực hiện 2 lần để làm mịn ảnh và lấp đầy các khoảng trống. Phép lọc này thường làm xê dịch ranh giới giữa mặt nước và đất liền khỏi vị trí chính xác của nó [4].

Ở giai đoạn tiếp theo, ảnh radar sau khi được tăng cường sẽ được biến đổi từ dạng dữ liệu 16 bit về dạng dữ liệu 8 bit. Khi đó biểu đồ giá trị độ xám sẽ được phân bố lại thành 256 mức độ xám. Biêu đồ này cũng cho phép xác định giá trị ngưỡng nhằm phân biệt giữa các đối tượng mặt biển và mặt đất. Việc phân đoạn ảnh sẽ sử dụng các giá trị ngưỡng nhận được từ bước xử lý trước đó nhằm phân tách các đối tượng mặt biển và mặt đất. Đồng thời, nó cũng được xử lý phân đoạn theo 2 giai đoạn để loại bỏ các đối tượng không mong muốn trên phần đất liền hoặc trên mặt biển với lưu ý là kích thước của các đối tượng mặt biển và đất liền thông thường là rất lớn. Việc xác định kích thước phù hợp (theo đơn vị pixel) để lấy hay bỏ các đối tượng này có thể dựa vào ảnh nắn trực giao. Đây là công đoạn quan trọng nhằm bảo toàn được tất cả các đối tượng đảo trong khi có thể loại bỏ tối đa các đối tượng không mong muốn khác để giảm thiểu công sức biên tập [5].

Sau đó, tìm kiếm đường ranh giới giữa mặt nước và đất được thực hiện bởi phép 
lọc Roberts cho phép tạo ra đường ranh giới có độ rộng 1 pixel thuận lợi cho quá trình dò tìm đường đẳng trị sau này. Sau quá trình này, đường ranh giới giữa mặt biển và đất liền sẽ được mở rộng bằng toán tử hình thái "Dilation" sử dụng phép lọc Mean để hiệu chỉnh phần xê dịch vị trí do ảnh hưởng của thuật toán này trong bước xử lý trước đó. Ảnh kết quả của bước xử lý này cần được biến đổi sang dạng nhị phân [9].

Việc xác định mặt biển và đất liền được thực hiện theo phương pháp dò tìm đường đẳng trị cùng với nguyên tắc lựa chọn đường rìa phía trong (inside edge) của đường bờ. Đường đẳng trị khi đó có thể được xuất sang các dạng file véc tơ phổ biến như dạng *.dxf hay dạng shapefile để sử dụng trong các phần mềm hệ thống GIS khác.

Cuối cùng, đường giữa mặt biển và đất liền dưới dạng file véc tơ có thể được làm trơn bằng các chức năng có sã̃n trong các hệ thống phần mềm như MGE, ArcGIS hoặc một số phần mềm khác. Sản phẩm này khi đó có thể sử dụng cho các bài toán phân tích của GIS.

\section{Kết quả và thảo luận}

Kết quả bình sai khống chế đối với cảnh ảnh vệ tinh TerraSAR-X cho độ chính xác mặt bằng là $\mathrm{m}_{\mathrm{x}}= \pm 0.864(\mathrm{~m})$ và $\mathrm{m}_{\mathrm{y}}= \pm 0.928$ (m). Độ chính xác này đảm bảo các yêu cầu đặt ra đối với việc chiết tách ranh giới giữa mặt biển và đất liền bằng ảnh radar cũng như đối với phần lớn các ứng dụng bản đồ khác.

Thực nghiệm cho thấy phương pháp này tỏ ra rất hiệu quả khi nhanh chóng tạo ra dữ liệu ranh giới giữa mặt biển và đất liền một cách liên tục mà không bị ngắt quãng với độ chính xác trung bình khoảng 1 - 2 pixel. Việc lựa chọn cảnh ảnh vệ tinh TerraSAR-X có góc tới lớn đã làm tăng sự phân biệt ranh giới giữa mặt đất và mặt nước do phần lớn năng lượng sóng radar khi tới mặt nước bị phản xạ ra xa khỏi vị trí ăng ten thu mặc dù trong một số trường hợp, dưới ảnh hưởng của sóng to và gió mạnh, một phần năng lượng phản xạ xảy ra trên bề mặt sóng hướng về phía ăng ten cũng sẽ được thu nhận. Bề mặt sóng nhấp nhô được thể hiện trên ảnh radar có màu sáng hơn thậm chí có thể sáng hơn một số đối tượng trên mặt đất có thể gây nên hiện tượng nhiễu trong quá trình xử lý ảnh tự động. Độ chính xác này cùng với độ phân giải cao của ảnh TerraSAR-X hoàn toàn có thể đáp ứng yêu cầu về độ chính xác trong nhiều ứng dụng. (Xem hình 3)

Tuy nhiên, phương pháp này cũng tồn tại một số hạn chế khi nó chịu ảnh hưởng của một số yếu tố như: nhiê̂̃u ảnh, các công trình dân sinh dọc bờ biển, sóng biển đang vỗ vào bờ, các vệt sóng do các tàu vận tải biển tạo ra trong khi di chuyển, dẫn đến một số nơi có sự sai lệch kết quả xác định vị trí chính xác của ranh giới giữa mặt biển và đất liền (Hình 3). Ngoài ra, đối với khu vực nghiên cứu Hạ Long - Cát Bà, do những đặc điểm kiến tạo địa chất mà trong khu vực này có nhiều đảo đá nhỏ, đồng thời đây cũng là khu vực cảng biển với nhiều tàu vận tải hàng hóa có kích thước lớn. Sự tương đồng về kích thước của các đối tượng này gây ảnh hưởng đến quá trình tự động chiết tách ranh giới giữa mặt đất và mặt nước, đòi hỏi kỹ thuật viên phải có đầy đủ thông tin về đặc điểm của khu vực trước khi thực hiện các bước xử lý dữ liệu tiếp theo. (Xem hình 4)

Một điểm khác cần lưu ý là đối với những khu vực có rừng ngập mặn ven biển thì ranh giới giữa mặt biển và đất liền được chiết tách tự động sẽ là đường biên của lớp thực phủ rừng ngập mặn. Do đó nó chưa phù hợp với các quy định hiện hành về việc thể hiện như một đối tượng trên các loại bản đồ đường bờ. Đặc biệt, đối với đặc điểm địa hình, địa chất của khu vực Hạ Long - Cát Bà với nhiều hòn đảo đá có độ dốc lớn thì yếu tố ảnh hưởng nhiều nhất đến độ chính xác 

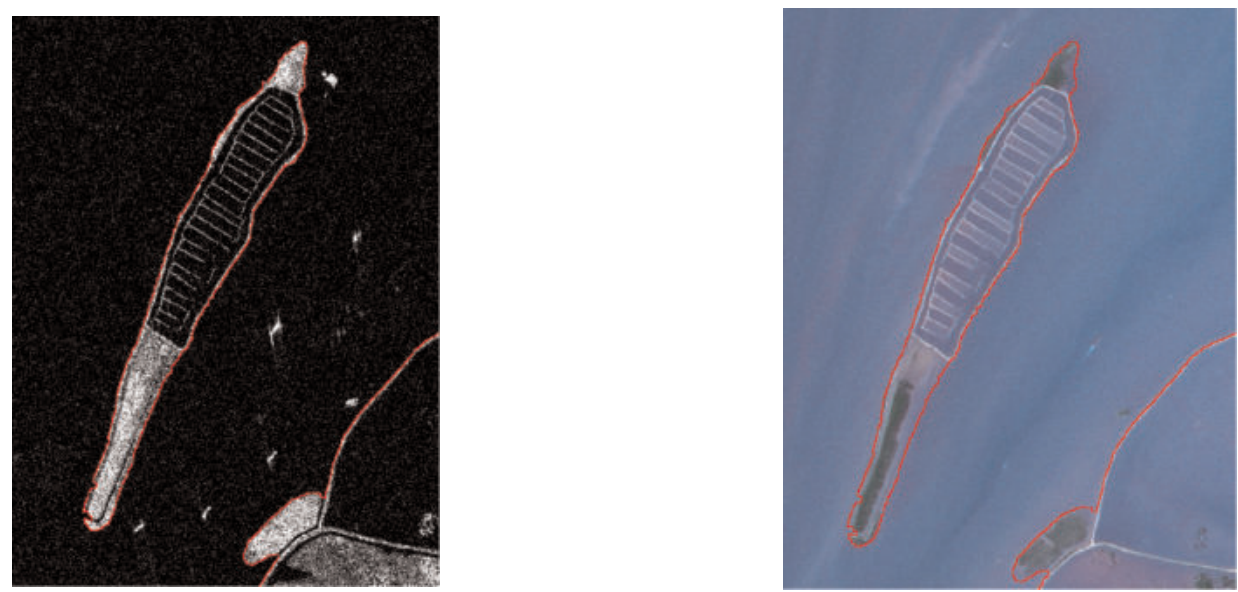

Hình 3: Ranh giới giữa mặt biển và đất liền

sau khi chiết tách đường chồng lớp lên ảnh gốc và ảnh SPOT

chiết tách ranh giới giữa mặt biển và đất liền là biến dạng hình học ảnh do hiện tượng khuất bóng trên ảnh radar. Để khắc phục hiện tượng như trong trường hợp này thì yêu cầu việc chiết tách ranh giới giữa mặt biển và đất liền cần phải được tiến hành trên cả cảnh ảnh theo quỹ đạo đi lên và cảnh ảnh theo quỹ đạo đi xuống.

\section{Kết luận}

ưng dụng ảnh vệ tinh radar trong việc tự động chiết tách ranh giới giữa mặt biển và đất liền phục vụ công tác kiểm kê đảo có nhiều ưu điểm khi nhanh chóng tạo ra ranh giới giữa mặt biển và đất liền một cách liên tục và giảm thiểu các công việc biên tập thủ công. Mặc dù vẫn còn một số hạn chế do các yếu tố nhiễu ảnh hưởng đến kết quả cũng như việc nhận biết các đối tượng ranh giới giữa mặt biển và đất liền bằng phương pháp xử lý ảnh còn khác biệt so với những quy định trong thực tế. Nhưng ngược lại, độ phân giải hình học cao của ảnh vệ tinh TerraSAR-X cho phép nhận được kết quả với độ chính xác mặt bằng tương đối tốt. Để có thể ứng dụng cho mục đích thành lập bản đồ ranh giới giữa mặt biển và đất liền hay các bản đồ địa lý trong thực tiễn thì cần phải có các bước xử lý thêm nữa phù hợp với những quy định kỹ thuật hiện hành. $\bigcirc$

\section{Tài liệu tham khảo}

[1]. Boak, E., Turner, I. 2005, "Shoreline definition and detection: A review", Journal of Coastal Research, Vol. 21, No. 4, pp. 688-703.

[2]. Elizabeth H., Boak, Ian L. Turner., 2005, Shoreline Definition and Detection: A Review, Journal of Coastal Research, Vol.23, No4, PP 688-703.

[3]. Suaza-Filho, P., Paradella, W. 2003, "Use of synthetic aperture radar for recognition of coastal geomorphological features, land-use assessment and shoreline changes in Bragança coast, Pará, Northern Brazil", Annals of the Brazilian Academy of Sciences, Vol. 75, No. 3, pp 341-356.

[4]. Liu, H., Jezek, K. 2004, "Automated extraction of coastline from satellite imagery by integrating Canny edge detection and locally thresholding methods", International Journals of Remote Sensing, Vol. 25, No. 5, pp 937-958.

[5]. Liu, H., Wang, L., Sherman, D. Wu, Q., Su, H. 2011, "Algorithmic foundation and software tools for extracting shoreline features from remote sensing imagery and LiDAR data", Journals of Geographic Information Systems, Vol. 3, pp 99-119. 

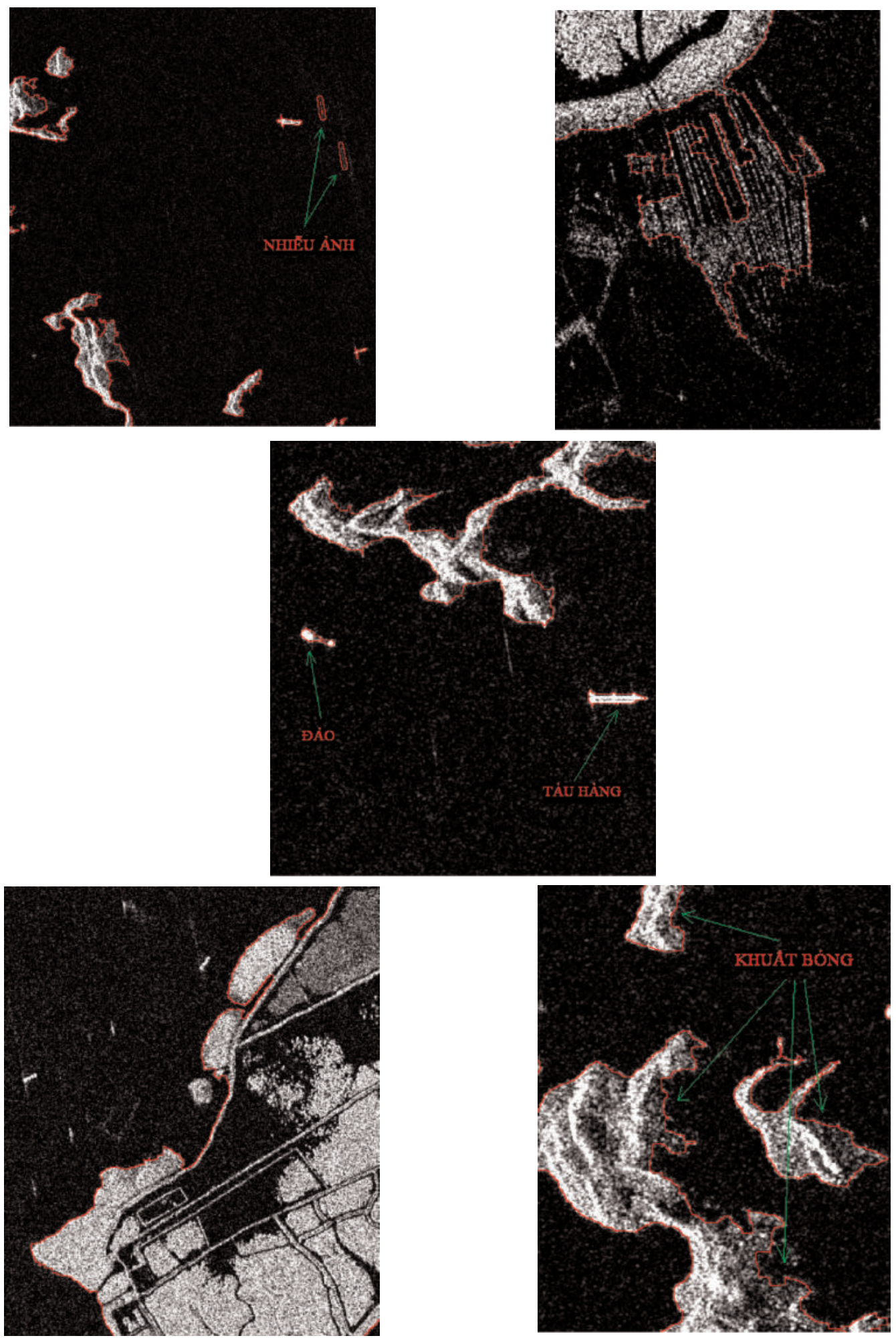

Hình 4: Ảnh hưởng của một số yếu tố đến

việc chiết tách ranh giới giữa mặt đất và mặt nước 
[6]. Lee, J., Jurkevich, I. 1990, "Coastline detection and tracing in SAR image", IEEE Transactions on Geoscience and Remote Sensing, Vol. 28, No. 4, pp. 662-668.

[7]. Mason, D.C., Davenport, J.I. 1996, Accurate and efficient determination of the shorelines in ERS-1 SAR images, IEEE Transactions on Geoscience and Remote Sensing, Vol. 34, No.5, pp. 1243-1253.

[8]. Baghdadi, N., Gratiot, N., Lefebvre, J.P., Oliveros, C. and Bourguignon, A. 2004,
Coastline and mudbank monitoring in French Guiana: contributions of radar and optical satellite imagery, Canadian Journal of Remote Sensing, Vol.30, pp. 109-122.

[9]. Hahmann, T. and Wessel, B. 2010, Surface Water Body Detection in HighResolution TerraSAR-X Data using Active Contour Models, In: Proceedings of the 8th European Conference on Synthetic Aperture Radar (EUSAR 2010), 7-10 June 2010, Aachen, Deutschland. ISBN 978-38007-3272-2. 0

\section{Summary}

\section{Application of TerraSAR-X imagery for island inventory}

MSc. Tran Tuan Ngoc, MSc. Nguyen Ha Phu

\section{Vietnam Remote Sensing Center}

Along more than $3260 \mathrm{~km}$ coastal line of Vietnam, there are more than 3000 islands. Almost all of our islands is quite small in term of the area, and they spread all over the large area of see, this distribution and the island size cause significant difficulty for island inventory, if the traditional technology such as field and aerial survey was applied. This paper introduces the method of using high resolution synthetic aperture radar imagery to automatically discrimination between island and the surrounding sea, that can help to inventory the islands. The paper also pointed out the factors that may impact to the island inventory using high resolution synthetic aperture radar imagery. $O$

Ngày nhận bài: 14/01/2013.

ĐỀ XUẤT QUY ĐỊNH Độ CHÍNH XÁC... (Tiếp theo trang 41)

\section{Summary}

Proposed regulation accuracy location on the boundary of the parcel, when the land value

MSc. Nguyen Phi Son

\section{Vietnam Institute of Geodesy and Cartography}

In this paper will present the results of calculation and proposed regulations on the correct position on the boundary of the parcel approach from the perspective of the economic value of land, land with high economic value will require high-accuracy measurements.Comes from the desire of transactions, transfer, tax, consignment area... land plots with error determining the value of the land is minimal, studies have established the relationship betweenrequired position of the error on the boundary of the parcel of land and asked to identify the value of the land. From this relationship combined with the survey results on six major soil groups with 1000 votes, we calculate the required accuracy corresponding to areas with higher economic value for each type of land use. $O$

Ngày nhận bài: 18/12/2012. 